Letter to Editor:

\title{
Violence Against Children and Strategies for Ending of This Phenomenon
}

\author{
Salman Khazaei ${ }^{1}\left(\right.$,, Yousef Veisani $^{2}$, Ensiyeh Jenabi ${ }^{3^{*}}$ (당
}

1. Research Center for Health Sciences, Hamadan University of Medical Sciences, Hamadan, Iran.

2. Psychosocial Injuries Research Center, Ilam University of Medical Sciences, Ilam, Iran.

3. Autism Spectrum Disorders Research Center, Hamadan University of Medical Sciences, Hamadan, Iran.

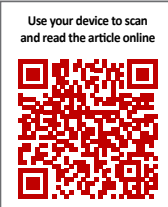

Citation Khazaei S, Veisani Y, Jenabi E. Violence Against Children and Strategies for Ending of This Phenomenon. Avicenna Journal of Neuropsychophysiology. 2018; 5(1):1-2. http://dx.doi.org/10.32598/ajnpp.5.1.1

http://dx.doi.org/10.32598/ajnpp.5.1.1

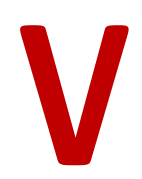

\section{Introduction}

iolence against children contains all forms of violence against children aged 2-17 years. This kind of violence covers all types of child maltreatment, including physical, sexual, and emotional abuse as well as neglect by strangers, their parents, other caregivers, peers, or romantic partners [1]. Unfortunately, the global statistics of violence against children show very high values. However, in the Middle East countries such as Iran, very little research has been conducted in this field [2]. In the following, we discuss the global situation of violence against children and how to prevent it according to the World Health Organization (WHO).

The results of a systematic review study extracted from 38 quality reports from 96 countries in 2015 showed that over half of all children in the world were the victims of violence in the previous year [2]. The evidence shows that nearly (25\%) of all adults had the experience of physical abuse in childhood, and (20\%) of the females and $(7.5 \%)$ of the males reported being sexually abused in their childhood. Estimates indicate that nearly 41000 homicide deaths occurred in children under 15 years each year in the world. Figure 1 shows the data of Violence against Children Surveys (VACS) for some countries, which indicates the high prevalence of this problem [3].
Child maltreatment imposed the increased risk of physical, sexual, and emotional problems such as homicide, anxiety and mood disorders, a tendency to smoking, risky sexual behaviors, illegal pregnancy, alcohol and drugs abuse, and contribution to a wide range of non-communicable diseases like heart diseases, cancer, suicide, and sexually-transmitted infections. Also, the costs of hospitalization increased, and the welfare of children reduced $[4,5]$.

WHO has introduced INSPIRE (seven strategies for ending violence against children) to end violence against children [6]. INSPIRE is a collection of strategies that through multi-sector collaboration tries to reduce violence against children in various contexts. These strategies include implementation and strengthening child protection laws, adherence to community norms and values, providing a safe environment, enough support through parents and caregivers, improving the economic situation, providing support services with the early response, and training life skills. The strategies mentioned above are most effective when implementing by rigorous monitoring and evaluation.

\section{* Corresponding Author:}

Ensiyeh Jenabi, PhD.

Address: Autism Spectrum Disorders Research Center, Hamadan University of Medical Sciences, Hamadan, Iran.

Tel: +98 (811) 38380496

E-mail:en.jenabi@yahoo.com 


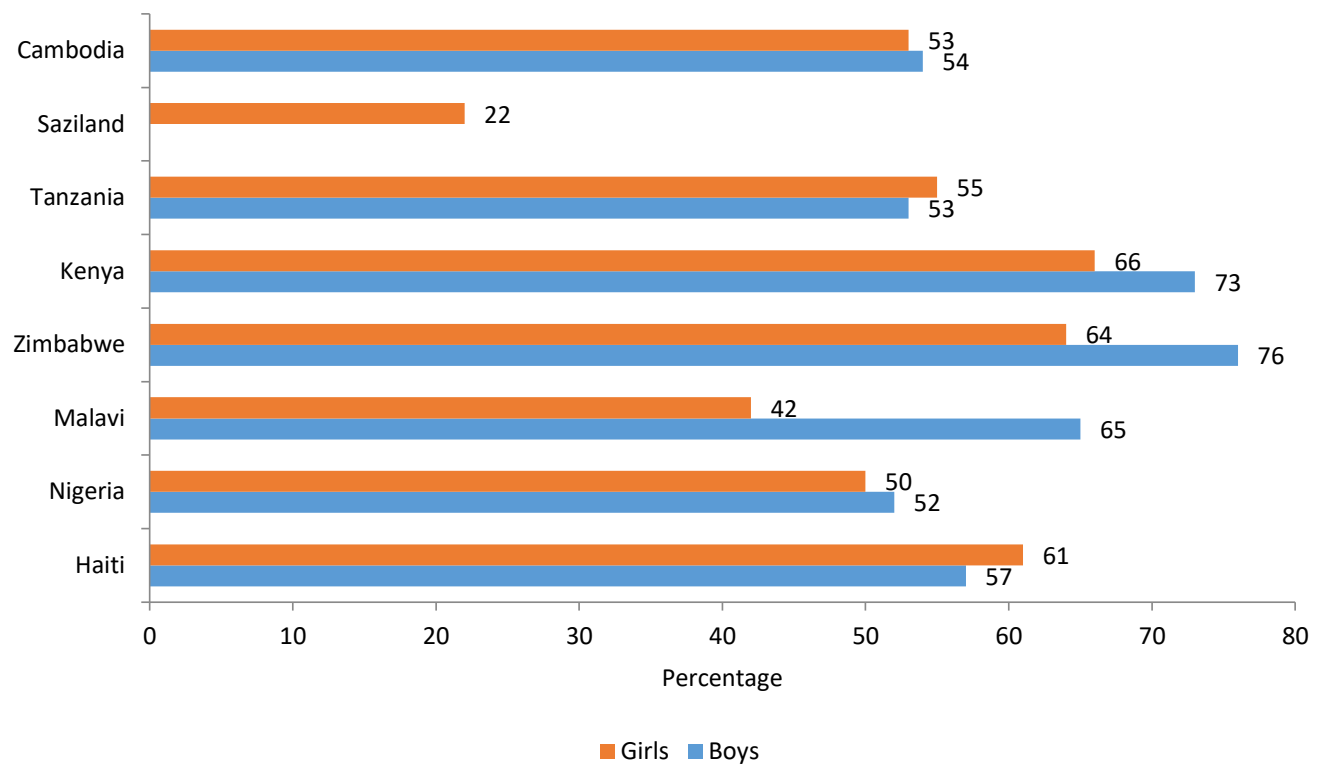

Figure 1. Data of violence against children surveys for some countries [3].

\section{Conclusion}

Violence against children hurts public health and increases health care costs. These remarkable data regarding violence against children in different countries demonstrate an urgent need for evidence-based interventions to reduce the high burden of this social anomaly. It is recommended that surveillance systems in societies should better cover all types of violence against children.

\section{Ethical Considerations}

\section{Compliance with ethical guidelines}

The study complies with standard ethical standards

Funding

This research did not receive any specific grant from funding agencies in the public, commercial, or not-forprofit sectors.

\section{Authors' contributions}

Design, literature search and discussion: All authors; First draft: Ensiyeh Jenabi, Yousef Veisani.

\section{Conflict of interest}

The authors declared no conflict of interest.

\section{References}

[1] Leeb RT. Child maltreatment surveillance: Uniform definitions for public health and recommended data elements. London: Centers for Disease Control and Prevention, National Center for Injury Prevention and Control; 2008.

[2] Hillis S, Mercy J, Amobi A, Kress H. Global prevalence of pastyear violence against children: A systematic review and minimum estimates. Pediatrics. 2016; 137(3):e20154079. [DOI:10.1542/ peds.2015-4079] [PMID] [PMCID]

[3] Chiang LF, Kress H, Sumner SA, Gleckel J, Kawemama P, Gordon RN. Violence Against Children Surveys (VACS): Towards a global surveillance system. Injury prevention. 2016; 22(Suppl. 1):i17-i22. [DOI:10.1136/injuryprev-2015-041820] [PMID] [PMCID]

[4] Gilbert R, Widom CS, Browne K, Fergusson D, Webb E, Janson S. Burden and consequences of child maltreatment in high-income countries. The Lancet. 2009; 373(9657):68-81. [DOI:10.1016/ S0140-6736(08)61706-7]

[5] Hillis SD, Mercy JA, Saul JR. The enduring impact of violence against children. Psychology, Health \& Medicine. 2017; 22(4):393-405. [DO I:10.1080/13548506.2016.1153679] [PMID]

[6] World Health Organization. INSPIRE: seven strategies for ending violence against children. Geneva: World Health Organization; 2016. 